\title{
Development of Pumping Motor Protection System
}

\author{
Dr.D.Princewinston ${ }^{1}$, M.Muthunayagam ${ }^{2}$, P.Sudharsun ${ }^{3}$, M.Mohamed Kaseem ${ }^{4}$ \\ ${ }^{1}$ Professor, HOD-Electrical and Electronics Engineering, \\ Kamaraj College of Engineering and Technology, Virudhunagar, Tamilnadu. \\ ${ }^{2}$ UG- Electrical and Electronics Engineering, \\ Kamaraj College of Engineering and Technology, Virudhunagar, Tamilnadu. \\ ${ }^{3}$ UG- Electrical and Electronics Engineering, \\ Kamaraj College of Engineering and Technology, Virudhunagar, Tamilnadu. \\ ${ }^{4}$ UG- Electrical and Electronics Engineering, \\ Kamaraj College of Engineering and Technology, Virudhunagar, Tamilnadu.
}

\begin{abstract}
Day today life get faster and automated to make the day easier. The world on today scenario, They need product that are user friendly and easy to use. Our product is useful in both the industry and home. Water is basic need of life. Ground water and fresh water is key source of water supply. We use motor or water pump to suck the water from the ground. During the summer the ground water level decrease, at that period of time motor cannot get the enough water to pump and it leads to the dry run of motor. Continuous run of motor at dry condition leads to increase in surge pressure, damage in coil, it cause damage in motor. To avoid this by using current sensor we detect the motor at loaded and unloaded condition. At unloaded condition or dry condition after particular period of time the motor will automatically turnoff. At set period of interval it again turn on and check the condition, if the motor is in loaded condition then the motor runs continuously. By this method we can safeguard the motor and avoid from serious disaster.
\end{abstract}

Keywords: ACS712 current sensor, Arduino microcontroller.

\section{INTRODUCTION}

Water is basic need of our life, in which $3 / 4^{\text {th }}$ of the earth is covered by water. Sea and ocean covers major of water source. Small portion of water is groundwater of $1.7 \%$ and small amount of water from glacier of $1.7 \%$ and very minute of amount of water is air.

Water play an important role in the world economy of each and every country. Approximately $70 \%$ of fresh water used by human for agriculture. Large quantity of water,ice and stream are used for cooling and heating in industry and home. Groundwater is used in both home and industry. Water table in the area decide the availability of water. Ground water recharge from the surface it is discharge from surface naturally at spring and seeps, Whereas ground water is often cheaper, more convenient and less vulnerable to pollution tan the surface water it is commonly used in home and in industry after retreatment of water it is used.

Human we get groundwater in many way. Major way is manmade well and water pump motor. There are many type of water pump motor major we use centrifugal pump to draw water from the ground. Now a days we use induction motor for centrifugal pump.

During summer, continuous run of motor leads to dry run of motor. Dry run of motor occur due to inadequate amount of liquid. This leads to a surge in pressure, flow or overheating that will instigate pump failure .As a result pumping element seize up on the shaft and also result is damage of motor. It occur mainly by the human error. To avoid this, By using Arduino microcontroller and current sensor we automatically turn off the motor by sensing the load by amount of current flow through it. Motor after the period of time automatically turnoff at no load condition.

\section{SYSTEM DESCRIPTION}

An Arduino NANO based microcontroller is used to control the working of pump and monitor at regular interval of time. It continuously evaluate the motor condition whether it is loaded and unloaded condition and also sensor used as 


\section{IARJSET}

\section{International Advanced Research Journal in Science, Engineering and Technology}

Vol. 8, Issue 6, June 2021

DOI: $10.17148 /$ IARJSET.2021.8625

the sensing unit. Current sensor used as sensing element of microcontroller. Arduino NANO is interfaced with current sensor, relay and convertor.

\section{COMPONENTS}
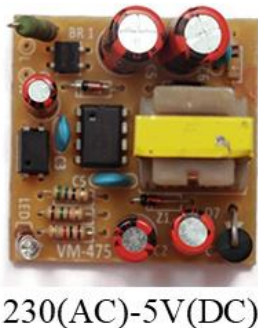

converter

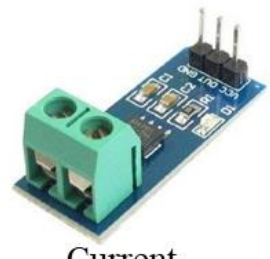

Current

Sensor(ACS712)

Purposed block diagram and circuit diagram

Block diagram

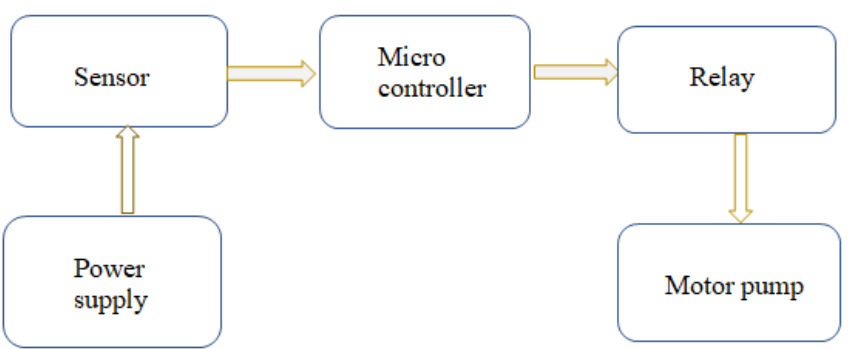

Circuit diagram

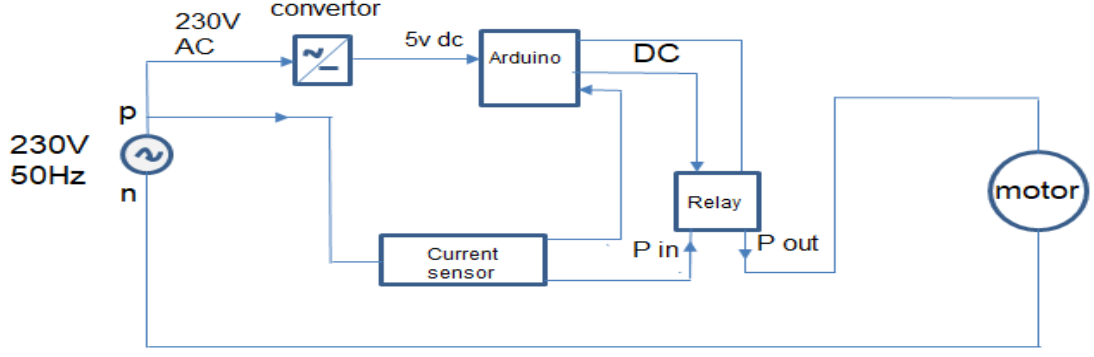

\section{HARDWARE AND EXPLANATION}

Controlling system is implemented in a $230 \mathrm{~V} 50 \mathrm{~Hz}$ power supply Ac supply is reduced from $230 \mathrm{~V}$ to $5 \mathrm{~V}$ using the step down transformer. The rectifier rectify the ac voltage to dc voltage for Arduino NANO microcontroller and it is connected with relay.

Sensing unit: The Arduino NANO is connected to the current sensor ACS712 for sensing the current of the motor and sense whether it is in loaded or unloaded condition and it check for every second.

Previous Analysis Work: Early we connected to 230v 50Hz power supply connected with rheostat, and Arduino NANO microcontroller connected with laptop for dc supply and then microcontroller is interfaced with current sensor, 


\section{IARJSET}

\section{International Advanced Research Journal in Science, Engineering and Technology}

Vol. 8, Issue 6, June 2021

DOI: $10.17148 / I A R J S E T .2021 .8625$

relay and ammeter. It also connected with LED lamp to check the program, connection and earlier analysis of work.

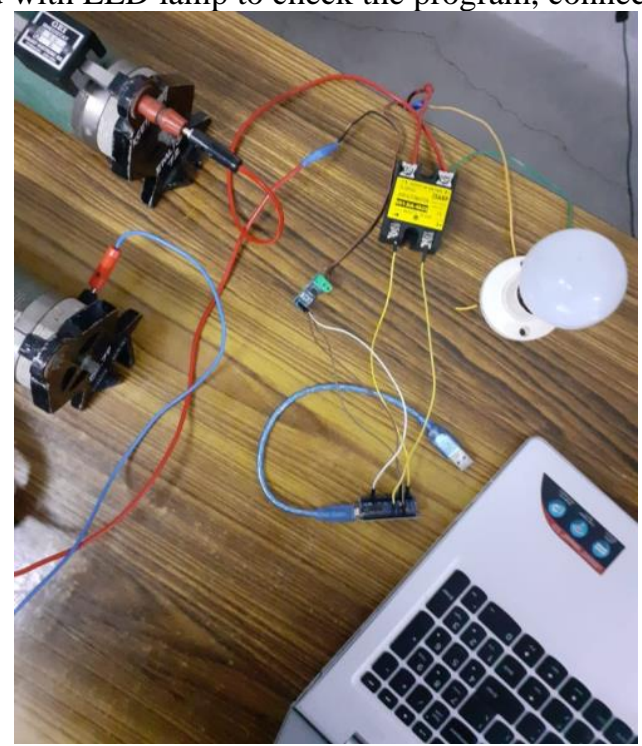

\section{SOFTWARE ANALYSIS}

The controlling system used is Arduino NANO microcontroller. It detect whether it is in loaded or unloading condition using the current sensor and transfer information to microcontroller, then it energize the relay.It is programed in that manner for the design of our project.

\section{PROGRAM ANALYSIS}

The motor we used for our design is $0.5 \mathrm{HP}$ motor with 3.5Amp as the rated current. By using Tong test we measure the current in loaded condition as 3.4-3.5Amp and at unloaded condition, current value measure less than the 3Amp. According to condition of ideal motor current at no load condition it measure about $1 / 3^{\text {rd }}$ or greater current and at loaded condition it measured is rated current.

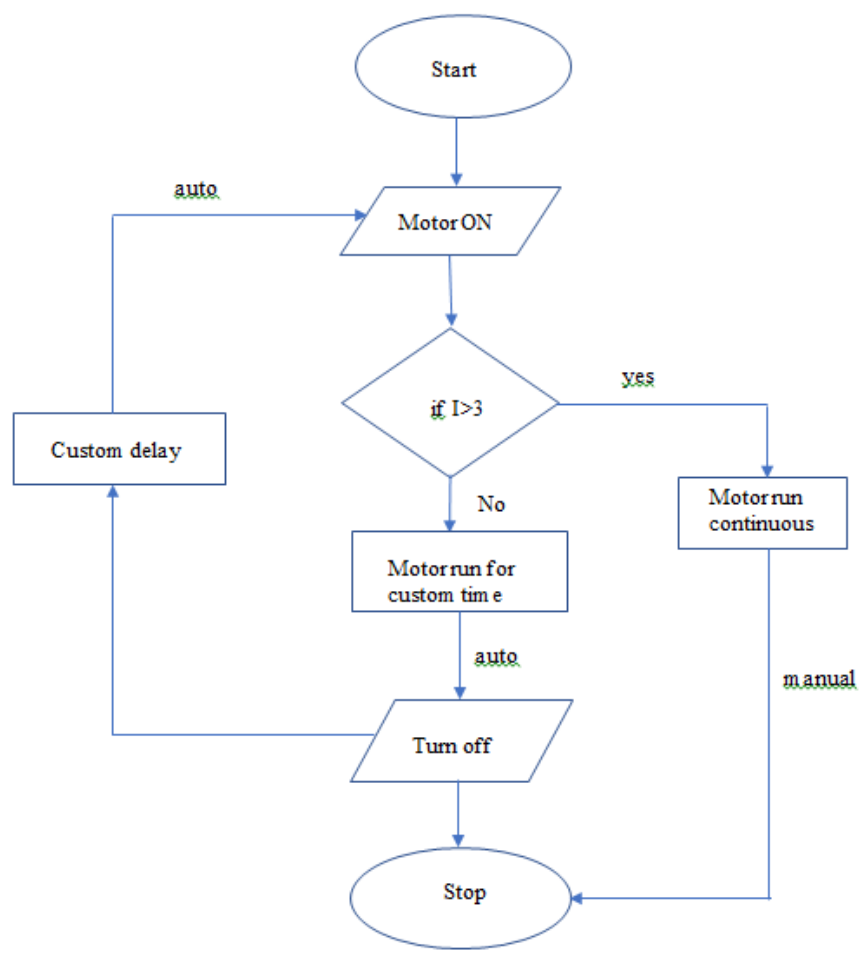




\section{IARJSET}

\section{International Advanced Research Journal in Science, Engineering and Technology}

Vol. 8, Issue 6, June 2021

DOI: $10.17148 /$ IARJSET.2021.8625

\section{Outcomes}

The working of system is controlled by an Arduino NANO microcontroller. During loaded or water flowing condition current read be more than $3 \mathrm{~A}$ and during unloaded or no water flow condition current read by the current sensor is less than 3A. At no load condition it check for $10 \mathrm{~min}$ and also check every second in between the either condition and relay get energized motor turn off in no load condition tripping occur in the circuit.

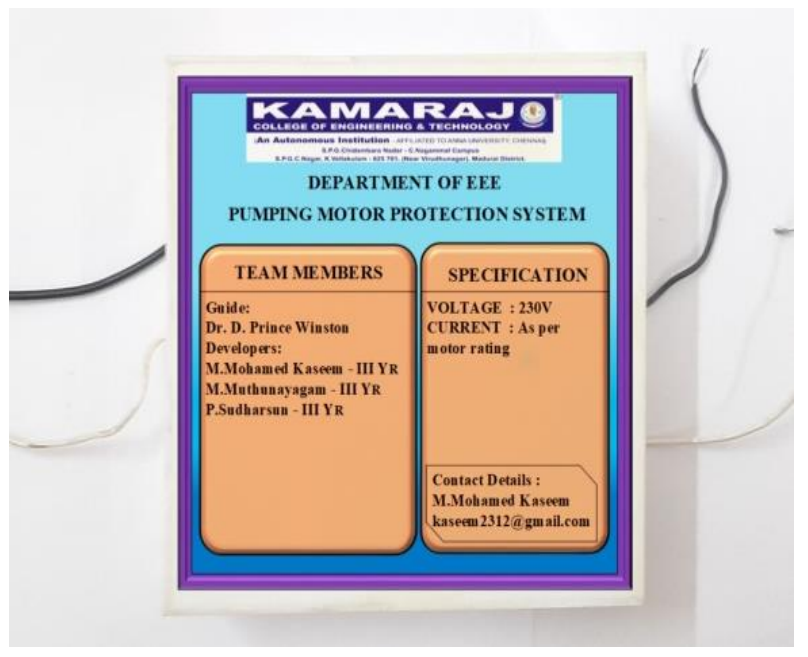

\section{CONCLUSION}

Development of pumping motor protection system can be achieved by this method using Arduino NANO microcontroller, current sensor and relay. The best effective way protection of motor from dry run of motor for long time which may leads to damage in winding earlier and can damage whole motor latterly can be avoided from this method. It is cheapest method of protection by current sensor. Our purpose of our project is to safeguard the every small device in motor in the effective way.

\section{FUTURE SCOPE}

In future, we use water level indicator in addition with this project and make fully automatic motor controlling system.

\section{REFERENCES}

[1]. . Antonova, M., Vasilieva, E., \& Zhezhera, I. (2017). The antisurge protection of a centrifugal compressor. 2017 International Conference on Modern Electrical and Energy Systems (MEES).

[2]. Microcontroller Based System for Bore-Well 3-Phase Motor to Avoid Dry Running" Aashish Joshi, Ashish Mali, Avdhut Jadhav, Nagesh Chavan. IJCEM International Journal of Computational Engineering \& Management, Vol. 17 Issue 3, May 2014 ISSN (Online)

[3]. Protection of Agriculture Motor Against Overloading and Dry run to prevent depletion of ground water", by Durga Hari Kiran bommanboina.

[4]. Intelligent motoring system for submersible motor protection Karthik Raveendran,Sai sachin.R,Alan Christy,Angel TS,Vipina Valsan 2020 Fourth World Conference on Smart Trends in Systems, Security and Sustainability (WorldS4)

[5]. Embedded System Based Submersible Motor Control for Agricultural Irrigation Using GSM and To Prevent It Against Over Loading, Dry Running and Single Phasing Automatically IJSRD - International Journal for Scientific Research \& Development| Vol. 2, Issue 07, 2014 | ISSN (online): 2321 -0613

[6]. Borewell water quality and motoring monitoring based on IOT gateway 2018 International Conferenceon Communication, Computing and Internet of Things (IC3IoT)

[7]. Ayyappan, G.S., Nikhil, N.K., Raja, R.M., Pandi, R.V., Angel, T.S., Babu, R.B.,"Electrical Motor Maintenance Techniques and Life Cycle AssessmentA Review with Case Studies"(2019) Proceedings of the 2019 2nd International Conference on Power and Embedded Drive Control, ICPEDC 2019, art. no. 9036543 , pp. $167-172$

[8]. Vaishakh, J.K., Vanitha, V., "Remote monitoring of BLDC motor using LabVIEW and zigbee", (2019) IOP Conference Series: Materials Science and Engineering, 561 (1), art. no. 012118.

[9]. Raviteja, K., Supriya, M., "IoT-Based Agriculture Monitoring System" (2020) Advance in Intelligent Systems \& Computing, 1079, pp.473-483

[10]. Gopinath, R., Santhosh Kumar, C., Ramachandran, K.I., Upendranath, V., Sai Kiran, P.V.R., "Intelligent fault diagnosis of synchronous generators" (2016) Expert Systems with Applications, 45, pp. 142-149

[11]. B. N. Getu, \& H.A. Attia "Automatic water level sensor and controller system", In the Proceedings of the 2016 IEEE International Conference on Electronic Devices, Systems and Applications (ICEDSA)

[12]. K. S. Varun, K. A Kumar, V. R. Chowdary, \& C. S. K. Raju "Water Level Management Using Ultrasonic Sensor(Automation)"

[13]. S.N.Durga1, M. Ramakrishna2, G. Dayanandam3, “Autonomous Water tank Filling System using IoT”, International Journal of Computer Sciences and Engineering, Vol.06, Issue.9, pp.123-141, 2018

[14]. Pavithra, D. S., and M. S. Srinath."GSM based Automatic Irrigation Control System for Efficient Use of Resources and Crop Planning by Using an Android Mobile." IOSR Journal of Mechanical and Civil Engineering (IOSR-JMCE) e-ISSN (2014): 2278-1684.

[15]. An analytical approach of parametric monitoring of induction motor using GSM , Snehal lande1, pooja jaiswal2, Priyanka rajgure3 IOSR journal for electronics and communication engineering(IOSRJECE) ISSN: 2278-2834 volume1, issue 3 ( may-- june ,2012) pp 01-07 